\title{
Complications of emergency obstetric hysterectomy in Gujarat, India
}

\author{
Bhoomika R. Chauhan ${ }^{1 *}$, Aarti J. Patel ${ }^{2}$ \\ ${ }^{1}$ Department of Obstetrics and Gynecology, GMERS Medical College, Himmatnagar, Gujarat, India \\ ${ }^{2}$ Department of Obstetrics and Gynecology, Smt. NHL Municipal Medical College, Ahmedabad, Gujarat,
}

Received: 19 August 2017

Accepted: 16 September 2017

\section{*Correspondence:}

Dr. Bhoomika R. Chauhan,

E-mail: prajjawalitresearch@gmail.com

Copyright: ( ) the author(s), publisher and licensee Medip Academy. This is an open-access article distributed under the terms of the Creative Commons Attribution Non-Commercial License, which permits unrestricted non-commercial use, distribution, and reproduction in any medium, provided the original work is properly cited.

\section{ABSTRACT}

Background: Emergency obstetric hysterectomy is defined as extirpation of uterus either at the time of cesarean section or following vaginal delivery, or within the puerperium to stop life threatening obstetric hemorrhage when all other measures fail. This study was conducted to study complications of emergency obstetric hysterectomy.

Methods: Out of 28552 patients, 45 patients operated for Emergency obstetric hysterectomy in Vadilal Sarabhai Hospital of Ahmedabad, Gujarat; during May 2010 to October 2012 were included in the study. Complications of the procedures were identified and analyzed.

Results: Hemorrhagic shock was the most common complication followed by fever. $15.55 \%$ (7 out 45 ) mothers were not saved even after the emergency obstetric hysterectomy.

Conclusions: Improvising procedural skill and post-operative care can reduce the complications of emergency obstetric hysterectomy.

Keywords: Emergency obstetric hysterectomy, Haemorrhagic shock, Hysterectomy

\section{INTRODUCTION}

Surgical removal of pregnant uterus or recently pregnant uterus is known as obstetric hysterectomy. ${ }^{1}$ As one of the markers of obstetric morbidity, it is one of the most risky and dramatic operations in modern obstetric, where the uterus is removed either during caesarean section or following caesarean section or immediately after vaginal delivery or during period of puerperium to reduce maternal morbidity and mortality. ${ }^{2}$ Emergency obstetric hysterectomy (EOH) is defined as extirpation of the uterus either at the time of caesarean section or following vaginal delivery, or within the puerperium period to stop life threatening obstetric haemorrhage when all other measures fail. Emergency obstetric hysterectomy is a lifesaving surgical procedure in life threatening conditions like uterine rupture, morbidly adherent placenta, coagulopathy or uncontrollable haemorrhage.
The commonest indication for Emergency obstetric hysterectomy which is cited in literature is postpartum haemorrhage due to uterine rupture and uterine atony. ${ }^{3}$

Placenta accrete, uterine vessel laceration, broad ligament haematoma or puerperal sepsis and bleeding from uterine incision are other indications. ${ }^{4,5}$

Intra-operative and post-operative bleeding leading to haemorrhagic shock, fever, urinary track injury, bladder injury, disseminated vascular injury and septicaemia are common complications of obstetric hysterectomy. ${ }^{4-7}$ Complications varies in frequency between elective and emergency hysterectomy.

This study was conducted to identify complications and their frequency in cases of emergency obstetric hysterectomy. 
Objectives recognized for the study were: identification of complication of emergency obstetric hysterectomy, determining the incidence and frequency of the respective complications

\section{METHODS}

This retrospective study was conducted after Institutional Ethical Committee Clearance during May 2010 to October 2012 in the Department of Obstetrics and Gynaecology at tertiary care hospitals of Vadilal Sarabhai Hospital of Ahmedabad, Gujarat, India.

Case of Emergency obstetric hysterectomy was defined as 'Patients undergone extirpation of the uterus either at the time of caesarean section or following vaginal delivery, or within the puerperium period to stop life threatening obstetric haemorrhage when all other measures fails.'

Patients who delivered between 1st may, 2010 to 31 st October 2012 including both days, after 24 weeks of gestations and undergone hysterectomy for obstetric purpose during delivery or within time of puerperium (42 days) were included in the study. Women who delivered before 24 weeks of gestation were not included in the study; patients undergone hysterectomy after the puerperium were also not included in the study.

Case records collected from the hospital records were studied for age, parity, indications, type of procedure and outcome of the procedure; data was compiled and analysed by Microsoft excel 2010 and Epiinfo 7.2.1 software. For statistical significance confidence interval was considered $>95 \%$ ( $\mathrm{p}$ value 0.05 ).

\section{RESULTS}

Out of 28552 patients, who delivered during the defined period in the hospital 45 patients operated upon for emergency obstetric hysterectomy were included in the study.

20 years was the smallest and 35 was the maximum age of the patient undergone obstetric hysterectomy. Maximum patients ( 7 out of 45 ) were 30 years old (Table $1)$.

Table 1: Age distribution in emergency obstetric hysterectomy.

\begin{tabular}{|ll|}
\hline Age (Years) & Frequency $(\mathbf{n = 4 5})$ \\
\hline $20-25$ & $14(31.11 \%)$ \\
\hline $26-30$ & $21(46.66 \%)$ \\
\hline $31-35$ & $10(20.22 \%)$ \\
\hline Total & 45 \\
\hline
\end{tabular}

Haemorrhagic shock was the most common complication of the emergency obstetric hysterectomy in which 5 were caesarean section and 7 were vaginal deliveries. Second most frequent complication was fever (Table 2).

Table 2: Incidence of complications of emergency obstetric hysterectomy.

\begin{tabular}{|l|l|}
\hline Morbidity/complications & $\begin{array}{l}\text { Obstetric } \\
\text { hysterectomy } \\
\text { emergency }(\mathbf{n}=45)\end{array}$ \\
\hline Haemorrhagic shock & $12(26.66 \%)$ \\
\hline Fever & $10(22.22 \%)$ \\
\hline Mortality & $7(15.55 \%)$ \\
\hline Bladder injury & $5(11.11 \%)$ \\
\hline $\begin{array}{l}\text { Disseminated intravascular } \\
\text { coagulation }\end{array}$ & $4(8.88 \%)$ \\
\hline Wound gaping & $4(8.88 \%)$ \\
\hline Acute renal failure (oliguria) & $3(6.66 \%)$ \\
\hline Paralytic ileus & $2(4.44 \%)$ \\
\hline Re-laparotomy & $2(4.44 \%)$ \\
\hline Urinary tract infection & $1(2.22 \%)$ \\
\hline Septicaemia & $1(2.22 \%)$ \\
\hline Recto vaginal fistula & $1(2.22 \%)$ \\
\hline
\end{tabular}

$15.55 \%$ ( 7 out 45 ) mothers were not saved even after the emergency obstetric hysterectomy; among them 3 patients were complicated by haemorrhagic shock, 2 were complicated by Disseminated intravascular coagulation, and one was complicated by acute renal failure; one patients was complicated by both haemorrhagic shock and disseminated intravascular coagulation.

6 patients were Primi Gravida, while 28 were Multi Gravida. One 31 years old $11^{\text {th }}$ Gravida, $3^{\text {rd }}$ Para patient operated upon emergency hysterectomy for placenta previa and postpartum haemorrhage did not have any complication.

One 31 years old, $4^{\text {th }}$ gravid $3^{\text {rd }}$ Para patient having vaginal delivery, undergone emergency hysterectomy for postpartum haemorrhage complicated recto-vaginal fistula.

\section{DISCUSSION}

Incidence of Emergency obstetric hysterectomy in the present study (1.57 per thousand) is comparable with other studies (Table 3). ${ }^{2,8-18}$

In this study, 26-30 years is the age group having highest frequency of the emergency obstetric hysterectomy, the obvious reason is the more frequency of pregnancy in the age group.

$62 \%$ (28 out of 45 ) cases were multigravida; uterine injury because of previous pregnancies, low haemoglobin level and repeated caesarean section are aggregating factors making multigravida vulnerable for obstetric hysterectomy. 
Table 3: Incidence of emergency obstetric hysterectomy in previous studies.

\begin{tabular}{|l|l|}
\hline Author & Incidence (Per 1000) \\
\hline Ekachai K et al & 0.55 \\
\hline Sohasrabhojanee M et al & 3.5 \\
\hline Ahmed S et al & 2.62 \\
\hline Siddiq N et al & 5.6 \\
\hline Marwaha P et al & 3.1 \\
\hline Sharma R et al & 5.4 \\
\hline Javed N et al & 4.2 \\
\hline Sheikh N et al & 6.3 \\
\hline Lamba J et al & 2.13 \\
\hline Zalla S et al & 1.97 \\
\hline Ara S et al & 3.8 \\
\hline George P et al & 0.10 \\
\hline Present study & 1.57 \\
\hline
\end{tabular}

Haemorrhagic shock was the most common complication, uterine injury, low haemoglobin level may be the aggravating factors for the complications. Poor postoperative care and wound infection are the cause of fever. Improper stitching, infections, poor postoperative care may be the factor for wound gaping. Bladder injury, paralytic ileus and uterine injury complications indicate required improvising operative skill.

\section{CONCLUSION}

Even after, increase in number of hospitals and upgradation of health care facilities, in India Obstetric hysterectomy rate is noticeably not reduced. The factors responsible are increasing incidence rate of caesarean sections, delaying marriage and pregnancy, low level of health education and malnourishment.

Improvising the skill of procedure, avoiding unnecessary caesarean sections and female health education are required steps to be taken to reduce complications of emergency Obstetric hysterectomy.

Funding: No funding sources

Conflict of interest: None declared

Ethical approval: The study was approved by the Institutional Ethics Committee

\section{REFERENCES}

1. Nwobodo E, Nandi D. Emergency obstetric hysterectomy in tertiary care hospital in Sokoto, Nigeria. Annals Med Health Sci Res. 2012;2(1):3740.

2. Shaikh N, Shaikh S, Shaikh J. Morbidity and mortality associated with obstetric hysterectomy. J Ayub Med Coll Abbottabad. 2010;22(2):100-4.
3. Anita, Wadhwani K. Emergency obstetric hysterectomy. J Obstet Gynecol India. 2005:55(2):132-4.

4. Zelop C, Harlow B, Frigoletto F, Safon L, Saltzman D. Emergency Peripartum Hysterectomy. Am J Obstet Gynecol. 1993;168:1443-8.

5. Caesarean Delivery and Peripartum Hysterectomy. In: Cunningham F, Kenneth L, Steven B, John H, Dwight R, Catherine. Williams's obstetrics. $23^{\text {rd }}$ ed. New York: McGraw Hill; 2011:545-562.

6. Najmi R. Caeserian and postpartum hysterectomy- a study from Lahore. J Coll Physicians Surg Pak. 1994;4:120-5.

7. Gupta S, Hooker J, Beynon JL, Gibson JRM. Obstetric hysterectomy. J Obstet Gynaecol. 1994;14:159-161.

8. Preetha G, Mini I, Jayasree V. Emergency peripartum hysterectomy for primary $\mathrm{PPH}$ an obstetrician's challenge. Int J Contemp Med Res. 2016;3(5):1265-1267.

9. Ekachai K. Obstetric Hysterectomy: A 14-Year Experience of Rajavithi Hospital 1989-2002. J Med Assoc Thai. 2006;89(11):1817-21.

10. Sohasrabhojanee M, Jindal M, Kamat A. Obstetric hysterectomy a lifesaving emergency. J Obstet Gynecol India. 2006;58:138-141.

11. Amad S, Mir I. Emergency peripartum hysterectomy: experience at Apex Hospital of Kashmir Valley. Internet J Gynecol Obstet. 2007;8(2).

12. Siddiq N, Ghazi A, Jabbar S. Emergency obstetrical hysterectomy $(\mathrm{EOH})$ : A life saving procedure in obstetrics. Pak J Surg. 2007;23:217-9.

13. Marwaha P, Kaur M, Gupta A. Peripartum hysterectomy - a five years study: J Obstet Gynecol India. 2008;58:504-6.

14. Sharma R, Shaheen, Pathak J. Peripartum Hysterectomy: A review of 70 cases. South Asian Federation Obstet Gynecol. 2009;1(2):19-21.

15. Javed N, Tahir S. Emergency obstetric hysterectomyone year review at Allied Hospital, Faisalabad. APMC. 2010;4(1):86-89.

16. Lamba J, Gupta S. Role of emergency hysterectomy in modern obstetrics. JK Sci. 2012;14(1):2-24.

17. Zia S, Rafique M, Rizwan A, Khan T, Shamrani A. Maternal outcome in emergency peripartum hysterectomy: minimizing the risk. South Asian Federation Obstet Gynecol. 2013;5(3):91-95.

18. Ara S, Fouzia U. Emergency obstetric hysterectomy. Professional Med J. 2015;22(1):100-5.

Cite this article as: Chauhan BR, Patel AJ.

Complications of emergency obstetric hysterectomy

in Gujarat, India. Int J Reprod Contracept Obstet

Gynecol 2017;6:4950-2. 